\title{
Transfer of Mother Tongue Rhetoric among Undergraduate Students in Second Language Writing
}

\author{
Narges Saffari ${ }^{1}$, Shahrina Md Noordin ${ }^{1}$, Subarna Sivapalan ${ }^{1} \&$ Nahid Zahedpisheh ${ }^{1}$ \\ ${ }^{1}$ School of Management and Humanities, Universiti Teknologi Petronas, Perak, Malaysia \\ Correspondence: Narges Saffari, School of Management and Humanities, Universiti Teknologi Petronas, Perak, \\ Malaysia. Tel: 60-13-467-8378. E-mail: narges.saffari1@gmail.com
}

Received: March 9, 2017

doi:10.5539/ies.v10n11p23
Accepted: May 24, 2017 Online Published: October 28, 2017

URL: https://doi.org/10.5539/ies.v10n11p23

\begin{abstract}
Mother tongue rhetoric transfer is unavoidable in ESL writings, especially for Iranian ESL learners, since Persian and English language is quite different. The paper discusses the negative transfer of mother tongue rhetoric in Iranian undergraduate ESL learners' writings from the perspectives of choosing rhetorical structure in English and Persian writing. In this regard, 50 intermediate undergraduate Iranian students who are a bachelor in engineering fields at two private higher education institutions located in Malaysia, are selected as participants to give their opinion about which style they prefer to use for both English and Persian writing. Statistical analysis of the participants' performance indicates that Iranian undergraduate students use the same rhetorical pattern for their both Persian and English writing and there is no consideration regarding the knowledge of L1 and L2 differences. The results also state that above $70 \%$ of the participants prefer to give a general comment about the topic and encourage readers at the end of the writing in their English and Persian essays.
\end{abstract}

Keywords: cultural rhetoric, English as a second language, writing, ESL students

\section{Introduction}

Alsamandi (2010) considers that second language writing is difficult and complex procedure. Moreover, Langan (2005) also says that writing consists of several phases such as discovering and developing, organizing, revising, and finally editing to present an effective, proper, and error-free piece. As stated by Lee (2003), the most significant matter which makes the process of writing more difficult and challenging is because most business and technical writing in all over the world is done in a second language. That is why second language writing is the one of the important aspects of the second language. Luchini (2010) says that one reason for this difficulty of writing for second language students is a lack of awareness regarding the process of writing. Based on his research, a broad scope of linguistic strategies and cognitive strategies are an essential requirement for writing procedure. L2 learners' knowledge and beliefs about writing may be culturally shaped. Researchers (Devin, Railey, \& Boshoff, 1993; Kasper, 1997; Victori, 1999) have suggested that L2 learners' knowledge and beliefs about writing may affect the effectiveness of their style to L2 writing tasks and the effectiveness of the outcome. That is, L2 writers may lack appropriate knowledge about the requirements and processes involved in undertaking an L2 writing task (Biggs, Lai, Tang, \& Lavelle, 1999). A coherent theory of L2 writing needs to include concern for more fully understanding students' knowledge and beliefs that may influence the learners' approach towards a writing task. Incidentally, this paper will discuss the negative transfer of mother tongue rhetoric in Iranian undergraduate ESL learners' writings from the perspectives of choosing rhetorical structure in English and Persian writing.

\section{Review of the Literature}

Contrastive rhetoric research looks at the organization of discourse and the rhetorical features in various languages. It offers an opportunity to address cross-cultural problems in writing faced by L2 writers. Research into this field was started by Kaplan (1966), who analyzed a large number of ESL essays written by international students from different cultural and linguistic backgrounds. He believed that people from different cultures used the rhetorical patterns of their native languages when organizing their English writing. Many studies such as "writing across language and cultures (Purves, 1988)", "annual review of applied linguistics (Kaplan, Tucker, \& Jones, 1983)", and "writing across language (Kaplan \& Connor, 1987)" support the theory of rhetorical structures which show that different languages have different cultural and rhetorical pattern in written texts. 
Kaplan (1967) believes that diversity in languages is the result of different word views and cultures. In other words, languages represent and repeat culture.

According to Kaplan (1972), each culture has its own structural pattern of writing which is called rhetoric. He explains more that rhetoric is a tool that writers use to convey their thought and ideas by representing their language. In other words, rhetoric consists of analysis factors, general words and data, explanation, and the combination of ideas (Kaplan, 1972).

Moreover, he says that rhetorical is not a fixed universal form among languages but it changes from cultures. In his study, he found and categorized the five different rhetorical structures from several languages which influence second language writing.

He believes that structure of English writing is vertical and straight which has upright and the flat surface of the organizational pattern. Other types of structure contrast to English language, involve Oriental structure such as Indo-European language writing pattern like, Arabic, Chinese, and Persian. In Arabic language, the rhetoric is like zigzags and spiral. Other examples can be said Roman and Russian languages that have an irregularly down falling spiral pattern.
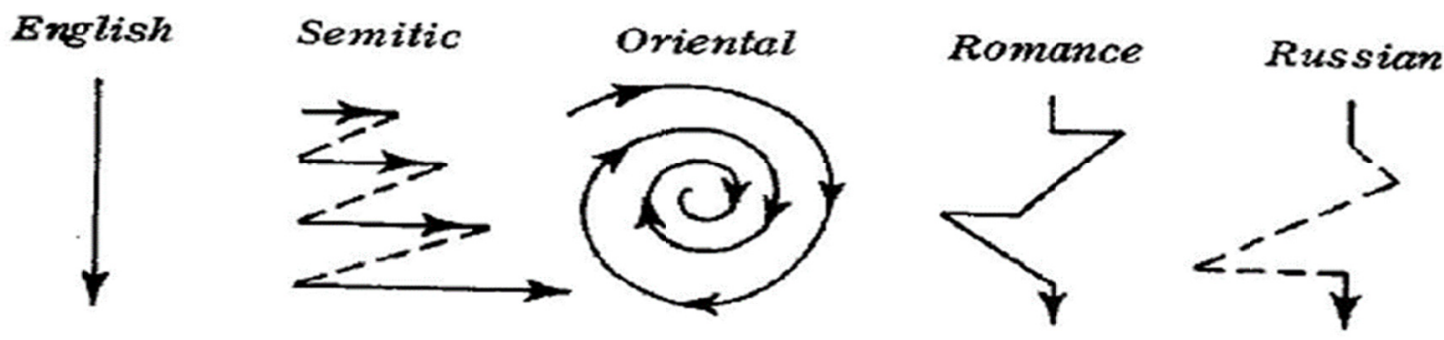

Figure 1. Rhetorical pattern (Kaplan, 1966)

As shown in figure above, these differences in languages sometimes lead students to transfer their first rhetorical pattern to the second language. Referring to Hong (2014) research, transfer consists of two parts, positive and negative. Although positive transfer assists learners to achieve more but negative transfer decreases the ability to study second languages.

Studies show that second language students unconsciously apply first language structures and pattern when they write in foreign languages (Abu-Rabia, Shakkour, \& Siegel, 2013). Consequently, the similar structures of the languages link together and learning to achieve effectively. However, regarding differences in rhetorical structures between languages, a transfer from the first language is not positive and effectively all the time. Differences in cultures lead to having unclear, incorrect, and unstructured text which is not acceptable from English native readers (Abu Rass, 2011). His study was on eighteen Muslim teachers. His findings show that their religion, Islam, influence on their English writing. Furthermore, their cultural transfer blocks developing academic writing skill. Moreover, in the study of comparison between Chinese and English structural pattern which conducted by Xing, Wang, and Spencer (2008), the result showed that the engagement with emails may improve cultural awareness of rhetorical differences and thus, student's ability in English writing had been developed significantly.

According to Kachru (1995), it is completely logical to make ESL writers aware of rhetorical patterns of English writing which on the whole can improve cultural understanding between languages. In a study conducted by Kuntjara (2005), an attempt was made to see whether there has been any cultural transfer in writings of Indonesians students. The study suggested that analyzing the rhetoric of a language is a complicated process though the findings confirmed the effect of raising awareness on increasing cultural understanding.

Students at the undergraduate level are in their foundation stage of their academic progress. Therefore, all students need to learn to join the language community of the discourse in order to be successful. Students from different backgrounds, such as students from diverse cultures and countries, definitely carry various discourse practices from their home communities to the university (Bizzell, 2004). Literature shows that in comparison to students from other countries, Iranian students look to be amongst those who face most struggles in writing 
English language texts (Kmyabi, 2016). According to Shokrpour and Fallahzadeh's (2007) report on Iranian EFL Medical students in second language writing, they discovered that Iranian students have problems in writing and language skills. They found that even though the students have difficulty in both areas (language \& writing skills), most of their problems come from writing skills. These studies found that the basic reasons for writing problems are first, second language students do not have acceptable knowledge rela ted to rhetorical and cultural patterns differences of English language compared with their first language which is Persian. And last but not least, the fact that most teachers during the General English Courses prefer to use mother tongue than English due to several reasons such as class time limitation, lack of proper additional material like audio-video player, the number of students in class. In this regard, students are not required to write English in class. This situation for Iranian students has not changed much till now. By finishing EFL classes, students are still unable to write easily with simplicity and correctness in vocabulary, idiom, and syntax. They are also unable to understand language as an essential element of culture and understand the principle ways in which the American culture differs from Iranian culture (Alijanian \& Dastjerdi, 2012). They cannot either understand the fact that American writing styles are culturally oriented (Rooholamini, 1986). Based on Saneh's (2009) statement, learner's culture can effect in the way of learning and it will be more notable when the learner tries to learn the second language. Many studies illustrate the effect of learner's culture and mother tongue on second language learning in Iran and how these can be barriers to master the second language i.e. English language. For example, Beigi \& Ahmadi (2011) did an analysis of Iranian writing style in comparison to Persian language and found out that English writing is deductive, linearity, straightforward nature, and explicitness; however, Persian writing are inductive, circularity, metaphorical nature, explicitness and the Start- Sustain-Turn-Sum structure.

Table 1. English and Persian rhetorical structures (Beigi \&Ahmadi, 2011)

\begin{tabular}{|c|c|}
\hline Characteristics of English writing style & Characteristics of Persian writing style \\
\hline Deductive, main idea stated at the first paragraph directly & $\begin{array}{l}\text { Inductive, general comments comes first and there is no direct statement of } \\
\text { main ideas }\end{array}$ \\
\hline $\begin{array}{l}\text { Writer states his/her point of view and gives reasons clearly } \\
\text { to get to the point }\end{array}$ & $\begin{array}{l}\text { Writer has the ability to repeat the main idea in several ways and by giving } \\
\text { his/her comment on topic try to attract readers attention }\end{array}$ \\
\hline More focus on authenticity and individualism of ideas & More focus on using others' statement, proverb, quotation \\
\hline $\begin{array}{l}\text { Write from general to specific (it is characterized by a } \\
\text { movement in thinking from a generalization to specific } \\
\text { details) }\end{array}$ & $\begin{array}{l}\text { Write from specific to general (paragraph begins with the details and leads } \\
\text { the reader to the generalization, which may be the thesis or the conclusion) }\end{array}$ \\
\hline $\begin{array}{l}\text { For supporting the arguments and persuade the readers, they } \\
\text { use the specific information }\end{array}$ & For supporting the arguments, they use famous advice like proverb \\
\hline
\end{tabular}

The reason why the study focuses on Iranian students is due to the various research findings on the different ways Persian and English language texts are written. For instance, Persian writing is deductive while English writing is inductive. This creates a challenge for Iranian students to structure their thoughts in producing English language texts. Due to the stark contrast between producing the two texts Persian and English language, this study has selected the Iranian students as its target respondents. Another reason that the study selects the Iranian students is due to the increase of Iranian students in Malaysian universities (Kmyabi, 2016).

\section{Methodology}

Questionnaire is designed to examine participants' beliefs about and experiences in English and Persian writing. The purpose of this retrospective survey is to understand the negative transfer of mother tongue rhetoric in Iranian undergraduate ESL learners' writings from the perspectives of choosing rhetorical structure in English and Persian writing. Students' prior experiences in writing Persian and English compositions are surveyed through their retrospective report on the frequency of rhetorical use in the opening (how to start up) and closing (how to end up) paragraph. Iranian undergraduate students are asked to express their perception about the use of different rhetorical styles of English and Persian writing through a five-point Likert scale from "Strongly Disagree" to "Strongly Agree". The response data on the 5-point Likert-type scale are divided into low frequency for "strongly disagree", "disagree", and "neither agree nor disagree" and high frequency for "agree" and "strongly agree". Descriptive statistics are generated using SPSS to examine the relative importance of the various factors investigated. The data gathered are tabulated and classified under the objective of the study.

The piloted questionnaire evaluated by using Cronbach's alpha Coefficient method to measure the reliability before the questionnaire is used in the main study. The results of the pilot study shows that almost all the values 
are above 0.70 indicating acceptable reliability. The Cronbach's Alpha is suitable for measuring internal consistency of the instrument (Hair et al., 2011). It is perceived that approximately 0.70 is an acceptable value and is a supported standard by numerous studies. As for pilot test, this research found that, the reliability of the construct range from 0.72 to 0.81 , all within the acceptable range.

Table 2. Construct, Dimension, number of items, Scales, and Cronbach alpha

\begin{tabular}{lcccc}
\hline Constructs & Dimension & Items & Scales & Cronbach's alpha \\
\hline \multirow{2}{*}{ Style } & English & 8 & E33_E41 & 0.72 \\
& Persian & 8 & F42_F49 & 0.82 \\
\hline
\end{tabular}

The participants are the Iranian undergraduate students at engineering-based universities namely: Universiti Teknologi Petronas and Multimedia University in Malaysia. It also should be stated that age and gender are not among the variables under study.

The proposed paper is consisted of 50 students (22 male and 28 female) who are asked to fill out the questionnaire. The samples of the students are drawn from the following: 25 sample from population of 32 students from UTP, age 20-22, IELTS 6 and above and 25 sample from population of 97 students from MMU, age 21-24, IELTS 6 and above.

\section{Result}

Table 3. Demographic result

\begin{tabular}{lcc}
\hline & & Percentage \\
\hline \multirow{2}{*}{ Gender } & Male & $44 \%$ \\
\multirow{2}{*}{ Age } & Female & $56 \%$ \\
\multirow{2}{*}{ Program } & $21-25$ (largest group) & $76 \%$ \\
Formal training in English (English courses taken) & Chemical & $32 \%$ \\
\hline
\end{tabular}

As shown in Table 3, among respondents, the major group of students is 21-25 years old (76\%) and most of the students study in the field of chemical and electronic with percentage of $32 \%$ and $24 \%$ respectively. Finally, $90 \%$ of the respondents had taken English course in English institution. All students had completed either two or three years of university education out of four years, plus, they completed all six years of high school education (three years of junior high school and three years in senior high).

Students' experiences in writing Persian and English compositions are measured through their report on the frequency of rhetorical use in the opening and closing paragraph. The response data on the 5-point Likert-type scale are divided into a low frequency for "strongly disagree", "disagree", and "neither agree", "nor disagree" and high frequency for "agree" "strongly agree" (Yu-Chuan, 2003). 
Table 4. Rhetorical structure use in English writing

\begin{tabular}{|c|c|c|c|c|}
\hline \multicolumn{2}{|l|}{ Items } & $\begin{array}{l}\text { Low Frequency } \\
\text { English }\end{array}$ & $\begin{array}{l}\text { High Frequency } \\
\text { English }\end{array}$ & $\begin{array}{l}\text { Percentage } \\
\text { English }\end{array}$ \\
\hline \multicolumn{5}{|c|}{ Style of English writing for opening (starting up) a text } \\
\hline 1) & I generate my idea (brainstorm) & 21 & 29 & $58 \%$ \\
\hline 2) & I directly start my opinion about topic & 26 & 24 & $48 \%$ \\
\hline 3) & I use others' statement and saying & 36 & 14 & $28 \%$ \\
\hline 4) & $\begin{array}{l}\text { I Introduce the topic briefly in general terms to get readers } \\
\text { interested }\end{array}$ & 14 & 36 & $72 \%$ \\
\hline \multicolumn{5}{|c|}{ Style of English writing for closing (ending up) a text } \\
\hline 1) & I summarize my point of view at the end of writing & 10 & 40 & $80 \%$ \\
\hline 2) & I recall vocabulary that I want & 27 & 23 & $46 \%$ \\
\hline 3) & I encourage reader to react & 16 & 34 & $68 \%$ \\
\hline 4) & I organize my text & 23 & 27 & $54 \%$ \\
\hline
\end{tabular}

According to Table 4, the frequency of respondents for opening a text in English writing is as below:

36 number of respondents (72\%) introduce the topic in general terms first to attract readers' attention in the beginning of the writing. Following that, 29 number of respondents $(58 \%)$ generate their idea and respectively, 24 and 14 number of students ( $48 \%$ and $28 \%$ ) directly start their point of view about the topic and mention others' statement as a quotation. Moreover, regarding students' perception on how they close writing, as it can be seen in table $4,80 \%$ of students want to summarize their point of view at the end of their writing while $68 \%$ of respondents encourage their reader at the end of text, $54 \%$ of them use text organization (it's a framework of a text's beginning, middle, and end). And finally, $46 \%$ of students said they recall the vocabulary which means that they focus on specific words that they want to remember their proper synonym for changing and revising.

Table 5. Rhetorical structure use in Persian writing

\begin{tabular}{|c|c|c|c|c|}
\hline Items & & $\begin{array}{l}\text { Low Frequency } \\
\text { Persian }\end{array}$ & $\begin{array}{l}\text { High Frequency } \\
\text { Persian }\end{array}$ & $\begin{array}{c}\text { Percentage } \\
\text { Persian }\end{array}$ \\
\hline \multicolumn{5}{|c|}{ Style of Persian writing for opening (starting up) a text } \\
\hline 1) & I generate my idea (brainstorm) & 15 & 35 & $70 \%$ \\
\hline 2) & I directly start my opinion about topic & 31 & 19 & $38 \%$ \\
\hline 3) & I use others' statement and saying & 31 & 19 & $38 \%$ \\
\hline 4) & $\begin{array}{l}\text { I Introduce the topic briefly in general terms to get readers } \\
\text { interested }\end{array}$ & 11 & 39 & $78 \%$ \\
\hline \multicolumn{5}{|c|}{ Style of Persian writing for closing (ending up) a text } \\
\hline 1) & I summarize my point of view at the end of writing & 15 & 35 & $70 \%$ \\
\hline 2) & I recall vocabulary that I want & 25 & 25 & $50 \%$ \\
\hline 3) & I encourage reader to react & 12 & 38 & $76 \%$ \\
\hline 4) & I organize my text & 21 & 29 & $58 \%$ \\
\hline
\end{tabular}

Table 5 shows that how the respondents rated their view of Persian rhetorical structure for opening and closing a text. Here it shows that around 39 of students introduce the topic by giving general comments on the topic. 35 of respondents prefer to generate their idea. Finally 19 of students quote a proverb and write their point of view directly at the beginning of the text. Regarding the paragraph ending in Persian writing, as it can be seen in table $5,76 \%$ of them want to encourage reader at the end of their writing. $70 \%$ said they summarize their point of view first and $58 \%$ of the respondents end up with text organization. And finally $50 \%$ of students recall the vocabulary before they finish the writing.

The results show that introduce the topic briefly in general terms to get readers interest and the style of generating the idea are the most popular styles for the opening paragraph. For the closing paragraph, the most popular styles are those of summarizing the main points of the essay item and encouraging the readers. The result shows that the two styles in each paragraph in both L1 \& L2 happen to include Persian rhetorical style. These findings suggest that students were likely to use Persian-preferred rhetorical styles while writing in English. 


\section{Discussion}

The findings show that the participants of the study use similar rhetorical patterns in both their L1 and L2 writings. The justification can be that these writers carried their L1 rhetorical patterns over to their L2 writings. The effects of students' L1 rhetorical knowledge on their L2 writing performance have confirmed to be much more complex than simple transfer, involving interference factors. Studies shows that acknowledge the cross-cultural differences of rhetorical structures, differences in rhetorical use do represent differences in English writing performance. In this paper, Persian-specific preferred structures shows to be significant in accounting for problematic organization in English compositions. Many studies have been conducted to investigate the differences between rhetorical patterns in first and second language writing. One of these studies is done by Ostler (1990). He studied on ESL test written collected from four different languages such as English, Arabic, Spanish, and Japanese. He found rhetorical differences. His result showed that second language students prefer to follow the style of writing which is based on their own culture.

According to above mentioned, in this paper, it has been expected that second language students arrange their English writing in the same way they write in the first language and their English writing format influenced by the first language rhetorical patterns and structure. And this can affect negatively on the quality of their English written texts.

Findings from this study suggest that Iranian ESL students transfer LI rhetorical knowledge, and this knowledge shows itself in different LI rhetorical patterns in L2 writing. This paper also proves that LI rhetorical patterns appear in the L2 essays. Moreover, LI rhetoric can influence many elements of L2 text production. As shown in table 5, the example of native and non-native writing characteristics regarding differences in rhetorical structure which conducted by Beigi and Ahmadi (2011) and cited by Sadeghi and Maleki (2015) this study supports Kaplan's (1966) claim of LI "interference," in the acquisition of certain L2 rhetorical patterns. This research has developed Kaplan's $(1966,1982)$ description of Iranian students' L2 essays as an "Oriental spiral." Kaplan claimed that Indo-European ESL students' L2 essays are characterized by "indirection," in which the topics are not discussed directly and, additionally, the sequencing of points in the students' L2 texts does not follow the sequencing considered logical in standard English discourse patterns. The focus of the essays, instead of at the beginning, frequently was near the middle or the end of the text. Instead of discussing the point directly, several examples were presented, leading the reader to draw the cognitive connections. This latter nonhierarchical pattern and certainly different from the English pattern.

Table 6. Example of native and non-native writing characteristics (Sadeghi \& Maleki, 2015)

\begin{tabular}{|c|c|}
\hline Native Writing & Characteristics \\
\hline $\begin{array}{l}\text { Initially, the title To Kill A Mockingbird is merely a cryptic phrase. Ultimately the reader } \\
\text { sees it as part of an important piece of symbolism that is, part of a process by which an } \\
\text { object represents something more important than itself, is associated with a wider } \\
\text { significance and eventually takes on the power of profound imaginative suggestion. } \\
\text { In many respects, the title is a key to some of the themes of the novel. In this way the } \\
\text { mockingbird image is the device by which the two plot elements are unified. The first part of } \\
\text { the novel is concerned with the Boo Radley mystery, and the second part is concerned with } \\
\text { the Tom Robinson trial. Both of these characters can be viewed as a mockingbird. Both are } \\
\text { harmless members of society and both are innocent people, yet, in some way, both are } \\
\text { persecuted by society. It is possible, therefore, to view the mockingbird as symbolizing the } \\
\text { Southern way of life a culture that emphasizes good manners, family background, and a } \\
\text { relaxed, unhurried pace of living - symbolic of a way of life that is beautiful, gentle and } \\
\text { fragile. } \\
\text { Unfortunately, another aspect of this way of life is racial segregation, a system that had been } \\
\text { tolerated for decades by many Southerners who knew in their hearts that it was morally } \\
\text { wrong. }\end{array}$ & $\begin{array}{l}\text { topic; It effectively understands the } \\
\text { significance of the title, both as an image and } \\
\text { theme and shows awareness of how it unifies } \\
\text { the structure of the novel. Effective use of } \\
\text { quotations to support ideas. }\end{array}$ \\
\hline Non-native Writing & Characteristics \\
\hline
\end{tabular}


When the girls and boys are teenager they aren't free as birds but after that they enter to the universities which are not separate and in this way they face a lot of difficulties. I think we should teach the girls and boys how to communicate with each other in this way they will prepare for future.

Primary school age is of the very important stages in life because this time a person's character is made. As the primary importance of this famous poem says if the first brick architect is tilt, tilted wall goes up Soraya. People are living in different levels of life and it makes some problems to children. Because they can't figure out what's going on in the crazy world and what exactly they think is what exactly they need.

Considering all, it is surely not a good idea. To have coeducational elementary schools in Iran.
Introduction has no direct main idea. It has been seen that main idea repeated frequently to attract readers' attention.

The use of proverb is visible however, it translated wrongly from Persian without consideration of English language characteristics.

Opinion of the writer regarding the topic comes at the conclusion

Finally, findings of the study show the narrow degree of awareness of cross-cultural rhetorical differences among Iranian learners of English in scope Second language acquisition researchers. The present study make an attempt to draw language learners' attention to the concept of language transfer with an emphasis on the fact that keeping language learners' two or more languages in isolation from one another is an impossible and undesirable outcome in learning another language.

\section{Pedagogical Implications}

As students develop more experience in second language learning, L2 rhetorical conventions need to be added as a supplement such as writing activities and exercises. Reading provides L2 input to learn about the text structures of written discourse and increase awareness of the cross-cultural differences and similarity. L2 writers need to learn and practice L2 writing conventions such as readers' expectations and preferred rhetorical styles, thus building up a rhetorical knowledge base comparable with that of their counterpart native speakers.

Cultural differences need to be explicitly taught in order to acculturate EFL writers to the English discourse community (Connor, 2002). Kuo (1995) suggests that the organizational patterns and text types should be taught to students. For example, a writer is supposed to take a position about the issue in an argumentative essay, sticking to his or her opinion, supplying evidence or examples to support his view (Oi \& Kamimura, 1995).

The implication of this paper is to teach students to avoid the negative influence and to reinforce the positive transfer. L2 writers need to be empowered not only by the awareness of cross-cultural differences but also by the facilitation of positive L1 influences.

Learning about differences and similarities between L1 and L2 may help L2 learners to write a more coherent text both in L1 and L2. Although both composition teachers and textbook writers recognize the importance of organization, they are often unable to help L2 students find strength from their own L1 repertoires. When it comes to the teaching and learning of L2 writing, cross-cultural differences have received much attention since contrastive rhetoric highlighted disparities and seemingly disregarded the similarities. Some L2 writing educators (e.g., Leki, 2000) have blamed contrastive rhetoricians for teaching students to write for native English speakers' expectations instead of expressing according to their own preferences. L2 learners should be provided with opportunities to connect with their L1 literacy skills in creating L2 texts.

\section{Conclusion}

According to the findings, the present paper linked with Kaplan (1987) and Matsuda's (1997) theory of contrastive rhetoric in that it finds differences between English and Persian organizational patterns in writing. Accordingly, it can be noticed that the differences between rhetorical features may appear from different world views as well as rhetorical cultural backgrounds of two languages (Ziahosseiny, 2013). This shows that writing is, in fact, a cultural phenomenon and the cultural backgrounds play a dynamic role in how an individual writes (Buckingham, 2008; Siepmann, 2006; Jalilifar, 2008; Victori, 1999; \& Samiee, 2008).

It is commonly believed that when an individual writes in a second or foreign language, they tend to transfer their native language to the target language (Baleghizadeh \& Pashaii, 2010). This transfer could very well be one of the main reasons why non-native students' writings sometimes get labeled as disorganized, digressive, drifting, waffling, vague, indirect, incoherent, irrelevant, and loosely structured (Lux, 1991; Ballard and Clanchy, 1991; Cortazzi and Jin 1997; Saneh, 2009).

The findings of this study have revealed the fact that raising awareness of similarities and differences between 
two languages among the teachers and students can benefit writing ability of Iranian Students of English. It may help students understand that their knowledge about their first language can affect the way they write in English; and it can help them to write closer to the standards required by international level. It can also help teachers to consider intercultural differences in writing while preparing and evaluating writing activities for their students and help them to improve their English writing abilities.

\section{Limitation}

With the growing number of Iranian students studying abroad, it is necessary to conduct more in depth studies regarding the differences between these students' native language and English. Unfortunately, up to now there is a great gap when it comes to Persian resources regarding the Persian rhetorical cultural norms. There is a specifically wider gap when we get to the structure of Persian argumentative style of writing. There is very scant literature in this regard. This gap needs to be filled with more studies in the future in order to create more effective techniques which are required in order to better communicate in English and be able to share ideas.

This study has some limitations regarding the analysis of one particular educational context with a self-selected population. Although results are not generalizable to every educational environment, they are a valuable addition to knowledge in this area. Only 50 undergraduate Iranian students served as the participants in this paper. Further studies with more participants should be conducted in order to generalize the findings.

Moreover, intermediate undergraduate Iranian students who studied at private higher education institutions, were selected as participants to give their opinion about which style they prefer to use for both English and Persian writings. Other researches can be conducted on students at other levels of English proficiency, specific age groups, or even with the same gender in order to see if similar results can be obtained.

\section{References}

Abu Rass, R. (2011). Cultural transfer as an obstacle for writing well in English: the case of Arabic speakers writing in English. English Language Teaching, 4(2), 206-212. https://doi.org/10.5539/elt.v4n2p206

Abu-Rabia, S., Shakkour, W., \& Siegel, L. (2013). Cognitive Retroactive Transfer (CRT) of Language Skills among Bilingual Arabic-English Readers. Bilingual Research Journal, 36(1), 61-81. https://doi.org/10.1080/15235882.2013.775975

Alijanian, E., \& Dastjerdi, H. V. (2012). The Use of Indirectness Devices in Persian and English Argumentative Written Discourse: A Cross-Cultural Perspective. International Journal of Linguistics, 4(3), 60. https://doi.org/10.5296/ijl.v4i3.1733

Alsamadani, H. A. (2010). The Relationship between Saudi EFL Students' Writing Competence, L1 Writing Proficiency, and Self-regulation. European Journal of Social Sciences, 16(1), 53-63.

Baleghizadeh, S., \& Pashaii, A. (2010). A comparison of English and Farsi rhetoric and its impact on English writing of Iranian students. Studies in Literature and Language, 1(5), 17-27.

Ballard, B., \& Clanchy, J. (1991). Assessment by misconception: Cultural influences and intellectual traditions. In L. Hamp-Lyons (Ed.), Second language writing in academic contexts (pp. 122-134). Norwood, NJ: Ablex Publishing Corporation.

Beigi, S. A. K., \& Ahmadi, H. (2011). A Contrastive comparison of structural and rhetorical patterns of. The Iranian EFL Journal, 167.

Biggs, J., Lai, P., Tang, C., \& Lavelle, E. (1999). Teaching writing to ESL graduate students: A model and an illustration. British Journal of Educational Psychology, 69(3), 293-306. https://doi.org/10.1348/000709999157725

Bizzell, P. (2004). The Intellectual Work of "Mixed" Forms of Academic Discourses. In C. Shroeder, H. Fox, \& P. Bizzell (Ed.), Alternative Discourses and the Academy (pp. 1-10). Portsmouth: NH: Boynton/Cook.

Buckingham, L. (2008). Development of English academic writing competence by Turkish scholars. International Journal of Doctoral Studies, 3, 1-18.

Connor, U. (2002). New directions in contrastive rhetoric. TESOL Quarterly, 36(4), 493-510. https://doi.org/10.2307/3588238

Cortazzi, M., \& Jin, L. (1997). Communication for learning across cultures. In D. McNamar, \& R. Harris (Eds.), Overseas students in higher education: Issues in teaching and learning (pp. 76-90). New York: Routledge.

Devin, J., Railey, K., \& Boshoff, P. (1993). The implications of cognitive models in L1 and L2 writing. Journal 
of Second Language Writing, 26(2), 203-225. https://doi.org/10.1016/1060-3743(93)90019-Y

Hair, J. F., Black, W. C., Babin, B. J., \& Anderson, R. E. (2011). Multivariate data analysis (7th ed.). Beijing: China Machine Press.

Hong, L. (2014). Study on the Negative Transfer of Mother Tongue in College Students' English Argumentative Writing. US-China Foreign Language, 12(1), 27-35.

Jalilifar, A. (2008). Discourse markers in composition writings: The case of Iranian learners of English as a foreign language. English Language Teaching, 1(2), 114-122. https://doi.org/10.5539/elt.v1n2p114

Kachru, Y. (1995). Contrastive rhetoric in World Englishes. English Today, 11, 21-31. https://doi.org/10.1017/S026607840000804X

Kaplan, R. B. (1966). Cultural thought patterns in intercultural education. Language and Learning: A Journal of Applied Linguistics, 16(1/2), 1-20. https://doi.org/10.1111/j.1467-1770.1966.tb00804.x

Kaplan, R. B. (1967). Contrastive rhetoric and the teaching of composition. TESOL Quarterly, 1(4), 10-16. https://doi.org/10.2307/3585808

Kaplan, R. B. (1972). The anatomy of rhetoric: Prolegomena to a functional theory of rhetoric; essays for teachers. Center for Curriculum Development.

Kaplan, R. B. (1987). Cultural thought patterns revisited. In U. Connor, \& R. B. Kaplan (Eds.), Writing across languages: Analysis of L2 Texts (pp. 9-21). Reading, MA: Addison-Wesley.

Kaplan, R. B., Jones, R. L., \& Tucker, G. R. (Eds.). (1983). Annual Review of Applied Linguistics (Vol. 3). Rowley, MA: Newbury House.

Kasper, L. F. (1997). ESL writing and the principle of nonjudgmental awareness: Rationale and implementation. Teaching English in the Two-Year College, 25(2), 60-68.

Kmyabi, Gol. (2016). Analyzing Contrastive Features in English and Persian Argumentative Writing. International Journal of Research Studies in Education, 5(2), 13-28.

Kuntjara, E. (2005). Cultural Transfer in EFL Writing: A Look at Contrastive Rhetoric on English and Indonesian. $k @$ ta, 6(1),13-29.

Kuo, C.-H. (1995). Cohesion and coherence in academic writing: From lexical choice to organization. RELC Journal, 26(1), 47-62. https://doi.org/10.1177/003368829502600103

Langan, J. (2005). College Writing Skills. Atlantic Cape Community College: McGraw-Hill.

Lee, S. (2003). Teaching EFL Writing in the University: Related Issues, Insights, and Implications. Journal of National Taipei Teachers College, 16(1), 111-136.

Leki, I. (2000). Writing, literacy, and applied linguistics. Annual Review of Applied Linguistics, 20, 99-115. https://doi.org/10.1017/S0267190500200068

Luchini, P. L. (2010). Evaluating the effectiveness of a complimentary approach to teaching writing skills. International Journal of Language Studies (IJLS), 4(3), 73-92.

Lux, P. A. (1991). Discourse styles of Anglo and Latin American college student writers. Arizona State University, Arizona.

Matsuda, P. K. (1997). Contrastive rhetoric in context: A dynamic model of L2 writing. Journal of Second Language Writing, 6(1), 45-60. https://doi.org/10.1016/S1060-3743(97)90005-9

Oi, K., \& Kamimura, T. (1995). A pedagogical application of research in contrastive rhetoric. Paper presented at the Annual Meeting of the Teachers of English as a Second Language Association, March 28-April 1, Long Beach, CA. (ED 392254).

Ostler, S. (1990). A study in the contrastive rhetoric of Arabic, English, Japanese, and Spanish (Doctoral dissertation, University of Southern California, 1990). Dissertation Abstracts International, 49(02), 245A.

Purves, A. C. (1986). Rhetorical communities, the international student, and basic writing. Journal of Basic Writing, $5,38,51$.

Purves, A. C. (1988). Introduction. In A. C. Purves (Ed.), Writing across languages and cultures (pp. 9-21). Newbury Park, CA: Sage Publications.

Rooholamini, S. D. (1986). A cultural manual in English as a foreign language for advanced students from Iran. 
New Jersey: Fairleigh Dickinson University.

Sadeghi, B., \& Maleki, M. (2015). Improving the Ability of Writing Argumentative Essays of Iranian EFL Learners by Raising Awareness of Rhetoric Transfer. Cumhuriyet University Faculty of Science Science Journal (CSJ), 36(3), 1300-1949.

Samiee, A. (2008). Writing and editing (9th ed.). Tehran: Samt Publications.

Saneh, N. A. (2009). Intercultural rhetoric in higher education: The case of Iranian students'textual practices in North American graduate schools. Ottawa: University of Ottawa.

Shokrpour, N., \& Fallahzadeh, M. H. (2007). A survey of the students and interns' EFL writing problems in Shiraz University of Medical Sciences. The Asian EFL Journal Quarterly, 9(1), 147-163. Retrieved from http://www.asian-efl-journal.com/March_2007_EBook.pdf

Siepmann, D. (2006). Academic writing and culture: An overview of differences between English, French and German. Meta: Translators' Journal, 51(1), 131-150. https://doi.org/10.7202/012998ar

Victori, M. (1999). An analysis of writing knowledge in EFL composing: A case study of two effective and two less effective writers. System, 27(3), 537-555. https://doi.org/10.1016/S0346-251X(99)00049-4

Xing, M., Wang, J., \& Spencer, K. (2008). Raising students' awareness of cross-cultural contrastive rhetoric in English writing via an e-learning course. Language Learning and Technology, 12(2), 71-93.

Yu-Chuan, J. C. (2003). Contrastive Rhetoric; an integrated account of the development of English writing by Taiwanese students.

Ziahosseiny, S. M. (2013). Contrastive analysis of Persian and English and error analysis. Tehran: RAHNAMA Publication.

\section{Copyrights}

Copyright for this article is retained by the author(s), with first publication rights granted to the journal.

This is an open-access article distributed under the terms and conditions of the Creative Commons Attribution license (http://creativecommons.org/licenses/by/4.0/). 